\title{
Carbohydrate analogue polymers by ring opening metathesis polymerisation (ROMP) and subsequent catalytic dihydroxylation
}

\author{
Stefan Meier, ${ }^{a}$ Harald Reisinger, ${ }^{b}$ Rainer Haag, ${ }^{b}$ Stefan Mecking, ${ }^{b}$ Rolf Mülhaupt ${ }^{* b}$ and \\ Franz Stelzer ${ }^{a}$ \\ a Institut für Chemische Technologie organischer Stoffe der Technischen Universität Graz, \\ Stremayrgasse 16, A-8010 Graz, Austria.E-mail: stelzer@ictos.tu-graz.ac.at; Fax: +433168738951 \\ ${ }^{b}$ Freiburger Materialforschungszentrum und Institut für Makromolekulare Chemie der \\ Albert-Ludwigs-Universität Freiburg i.Br., Stefan-Meier-Straße 21, D-79104 Freiburg i.Br. Germany. \\ E-mail:mulhaupt@uni-freiburg.de
}

Received (in Cambridge, UK) 18th January 2001, Accepted 28th March 2001 First published as an Advance Article on the web 17th April 2001

Ring opening metathesis poymerisation (ROMP) followed by catalytic dihydroxylation affords macromolecules with 1,2-diol structures. These new macromolecular compositions represent $C$-glycoside analogues of ribofuranose polymers that are thermally and hydrolytically stable.

Carbohydrate-protein interactions play an important role in many biological processes. Polysulfates derived from carbohydrates were recognized as potent and selective inhibitors of the in vitro replication of HIV and other enveloped viruses. In the case of sulfated dextrans the activity strongly depended on the molar mass of the oligosaccharides. ${ }^{1,2}$ The design of new carbohydrate-analogue polymers is of special interest in polymer chemistry and life sciences-applications range from drug systems to novel biocompatible materials and surface coatings. Ring-opening metathesis polymerisation (ROMP) offers attractive potential for the synthesis of well defined carbohydrate analogue polymers. The modern catalyst generations, developed by Schrock and Grubbs, tolerate polar groups and afford living polymerisation which is the key to molar mass control. Novel families of ROMP glycopolymers were prepared by Kiessling, Schrock, Grubbs and co-workers ${ }^{3-7}$ using sugarsubstituted derivatives of norbornene and 7-oxanorbornenes as monomers. Since conventional polysaccarides are prone to metabolic degradation by glycosidases due to their glycosidic linkages, ${ }^{2}$ hydrolytically stable carbohydrate-analogue compounds without glycoside linkages in the backbone represent interesting candidates for biomedical applications (Fig. 1).

Here we present a versatile synthetic method for the preparation of novel polyribofuranose analogue polymers which do not contain glycoside linkages between the monomeric units in the polymer backbone that are prone to metabolic degradation by glycosidases. This should provide an oligosaccharide analogue structure with improved biocompatibility and longer half-life times. Initial research on related oligosaccharide-analogue polymers was reported by Clark and Lee ${ }^{8}$ who used ROMP of 7-oxanorbornene diol derivatives. Since the double bonds of the polymer backbone were hydrogenated, the resulting saccharide-analogue polymers contained only two

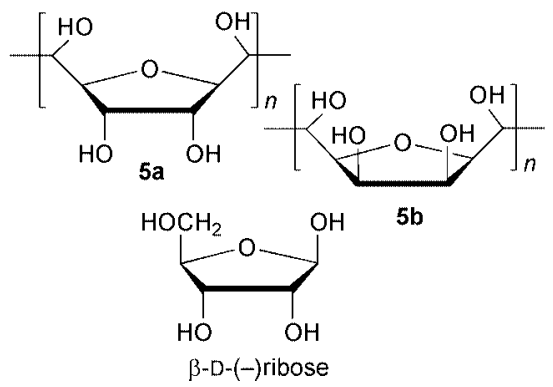

Fig. 1 Comparison between $\beta$-D- $(-)$ ribose and the novel carbohydrate analogue polymers $\mathbf{5 a , b .}$ hydroxy groups per repeating unit. The objective of our research was the synthesis of polymers containing fully hydroxylated repeating units. These are pseudo-polyribofuranoses, with structures very similar to those of natural carbohydrates. The synthetic strategy displayed in Scheme 1 employs ROMP of dihydroxy-substituted bicyclic olefin monomers and subsequent dihydroxylation of the double bonds in the polymer backbone.

Both pure 2-exo, 3-exo-7-oxanorbornene diol 1a and the corresponding endo isomer $\mathbf{1 b}$ were synthesized according to a literature procedure. ${ }^{9}$ Unfortunately, all attempts to perform ring-opening metathesis polymerisation in water, employing the water soluble Grubbs catalyst $\mathrm{RuCl}_{2}(=\mathrm{CHPh})$ $\left[\mathrm{Cy}_{2} \mathrm{PCH}_{2} \mathrm{CH}_{2} \mathrm{~N}\left(\mathrm{CH}_{3}\right)_{3}{ }^{+} \mathrm{Cl}^{-}\right]_{2} 7$ failed. Therefore, compounds $\mathbf{1 a}$ and $\mathbf{1 b}$ were transformed into their corresponding ketals $\mathbf{2 a}$ and $\mathbf{2 b}$ as reported by Schrock and co-workers. ${ }^{10}$ ROMP in THF gave high yields (80-90\%) using the well known Grubbs catalyst 6. The monomer to catalyst ratio was varied in order to obtain polymers with different molecular masses. Properties of the obtained polymers are listed in Table 1 . The resulting polymers 3a,b were soluble in THF, acetone, $\mathrm{CHCl}_{3}$ and $\mathrm{CH}_{2} \mathrm{Cl}_{2}$ but not in water or methanol. A polydispersity index $M_{\mathrm{w}} / M_{\mathrm{n}}$ of 1.5 , determined by size exclusion chromatography (SEC), reflects a relatively narrow molecular mass distibution ( $c f$. Table 1). A significant difference was observed with respect to the cis/trans double bond ratio in $\mathbf{3 a}$ and $\mathbf{3 b}$, respectively. The cis double bond content of $\mathbf{3 a}$ was $30 \%$ compared to $80 \%$ for $\mathbf{3 b}$.
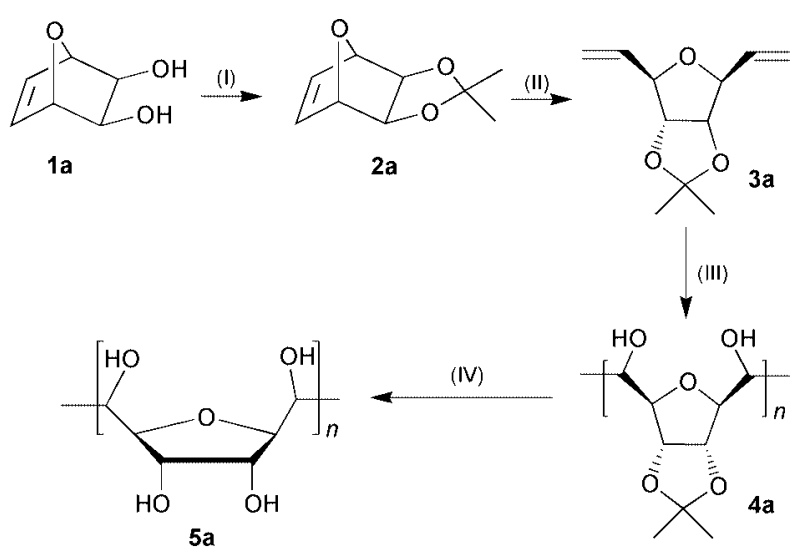

same reaction sequence for $1 \mathrm{~b}$

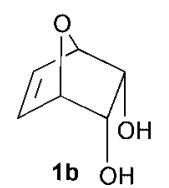

Scheme 1 Synthesis of the pseudo polyribofuranoses $[\mathbf{a}=$ exo, $\mathbf{b}=$ endo; (I), $c f$. ref. 10; (II), $\mathrm{RuCl}_{2}(=\mathrm{CHPh})\left(\mathrm{PCy}_{3}\right)_{2}$ (6), THF; (III), cat. $\mathrm{OsO}_{4}, \mathrm{NMO}$, acetone, $\mathrm{H}_{2} \mathrm{O}$, $\mathrm{MeOH}$; (IV), $\mathrm{CF}_{3} \mathrm{CO}_{2} \mathrm{H}-\mathrm{H}_{2} \mathrm{O}$ (9:1 vol. ratio)]. 
Table 1 Properties of $\mathbf{3 a}, \mathbf{b}$ and $\mathbf{4 a}, \mathbf{b}$

\begin{tabular}{lllllll}
\hline & $\begin{array}{l}{[\mathrm{M}] /} \\
{\left[[\mathrm{Ru}]^{a}\right.}\end{array}$ & $\begin{array}{l}M_{\mathrm{n}} / \\
\mathrm{g} \mathrm{mol} \mathrm{mol}^{-1 b}\end{array}$ & $\mathrm{PDI}$ & $T_{\mathrm{g}} /{ }^{\circ} \mathrm{C}^{c}$ & $\sigma_{\mathrm{c}} / \mathrm{mol}^{d}$ & $\sigma_{\mathrm{E}} / \mathrm{mol}^{e}$ \\
\hline endo & 25 & 7100 & 1.50 & n.d & 80 & 71 \\
& 50 & 12200 & 1.50 & 155 & 82 & 71 \\
& 75 & 14800 & 1.47 & 156 & 82 & 69 \\
exo & 50 & 19300 & 1.42 & 85 & 33 & n.d. \\
& 75 & 33900 & 1.42 & 86 & 34 & n.d. \\
& 100 & 36600 & 1.51 & 86 & 30 & n.d.
\end{tabular}

${ }^{a}$ Monomer to catalyst ratio. ${ }^{b}$ Determined for $\mathbf{3 a}, \mathbf{b}$ in $\mathrm{CHCl}_{3}$ against PS standard. ${ }^{c}$ Obtained for $\mathbf{3 a}, \mathbf{b} .{ }^{d}$ Content of cis double bonds in $\mathbf{3 a}, \mathbf{b}$. ${ }^{e}$ Content of erythro diols in $\mathbf{4 a}, \mathbf{b}$.

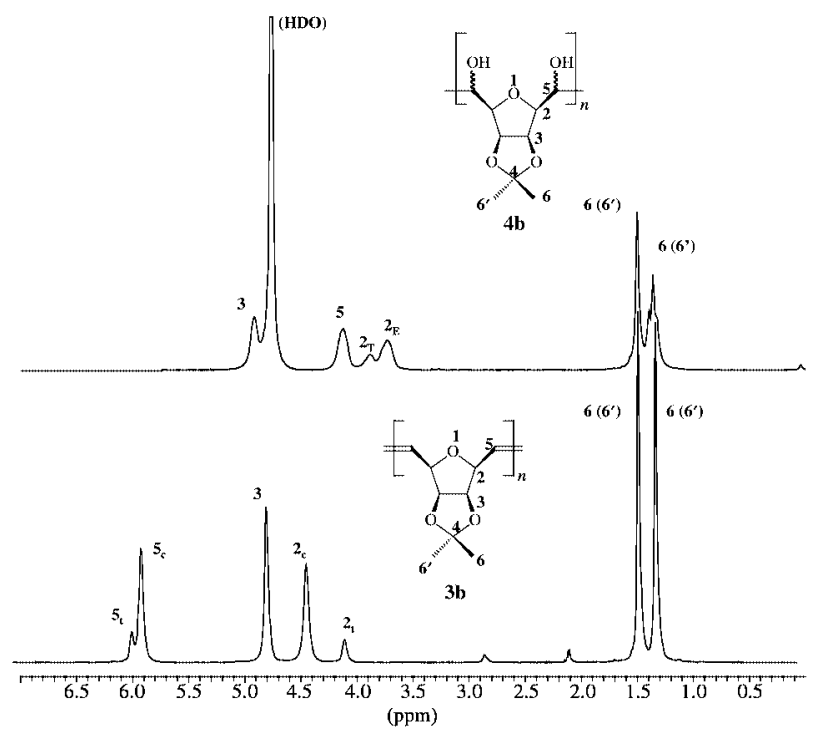

Fig. $2{ }^{1} \mathrm{H}$ NMR spectrum of $\mathbf{3 b}$ (acetone-d6, $300 \mathrm{MHz}$ ) in comparison to $\mathbf{4 b}$ $\left(\mathrm{D}_{2} \mathrm{O}, 300 \mathrm{MHz}\right)$.

The NMR-peaks were assigned based on COSY and DEPTNMR techniques and by comparison with chemical shifts of related structures. ${ }^{11}$ It is noteworthy that the exo and endo polymers also differ strongly in their glass transition temperatures $\left(T_{\mathrm{g}}\right)\left(\mathbf{3 a} T_{\mathrm{g}}=85^{\circ} \mathrm{C}, \mathbf{3 b} T_{\mathrm{g}}=155^{\circ} \mathrm{C}\right)$.

So far, typical polymer analogue reactions for the derivatisation of the double bonds produced by ROMP have employed sulfonation, hydrogenation, the formation of carbonamide ${ }^{12}$ and epoxidation. ${ }^{2,13}$ In order to produce the desired pseudopolyribofuranose structures we decided to dihydroxylate the double bonds in the backbone of the ROMP polymers $\mathbf{3 a}, \mathbf{b}$. To the best of our knowledge this is the first time that successful catalytic dihydroxylation of ROMP polymer has been achieved. While catalytic dihydroxylations are well known for many low molecular weight oligoalkenes $14 a$ it has rarely been successfully applied in polymer functionalisation. ${ }^{14 b}$

It is even more surprising that for the ROMP polymer $\mathbf{3 a} / \mathbf{b}$ a quantitative conversion of all double bonds into 1,2-diol structures could be achieved. SEC measurements confirmed that polymer degradtion did not occur during dihydroxylation. In the ${ }^{1} \mathrm{H}$ NMR spectra displayed in Fig. 2 the signals at $\delta=$ $5.86 \mathrm{ppm}$ and $5.94 \mathrm{ppm}$, which are assigned to the cis and trans double bonds of $\mathbf{3 b}$, completely disappeared after the dihydroxylation step. The signal for the protons in the 5 position was shifted to $\delta=4.1 \mathrm{ppm}$. The signal for the proton in the allylic position to the cis and trans double bonds $2 \mathrm{c}, 2 \mathrm{t}$ were shifted from $\delta=4.38 \mathrm{ppm}$ and $4.04 \mathrm{ppm}$ to $3.8 \mathrm{ppm}$ and 3.6 ppm respectively. In accordance with the dihydroxylation of double bonds of low molecular weight compounds, the cis double bonds are converted selectively to erythro diols and the trans double bonds to the corresponding threo diols. ${ }^{15}$ In the case of $\mathbf{3 b}$ the dihydroxylation method described for oligoalkenes $^{14 a}$ and polyalkenes ${ }^{14 b}$ was well suited to obtain the fully hydroxylated pseudo-polyribofuranose $\mathbf{4 b}$ which was completely water and methanol soluble. However, it was not soluble in THF, acetone and other organic solvents. In the case of $\mathbf{3 a}$ the fully dihydroxylated polymer $\mathbf{4 a}$ was only partially soluble in water but fully soluble in methanol. Therefore methanol was added instead of water as medium for the dihydroxylation in order to achieve a quantitative conversion. After deprotection of the ketal groups of $\mathbf{4 b}$ by means of $\mathrm{CF}_{3} \mathrm{COOH}-\mathrm{H}_{2} \mathrm{O}(9: 1 \mathrm{vol}$. ratio) a water insoluble polymer $\mathbf{5 b}$ was obtained which formed fine needles after precipitation from solution. These needles were only soluble in DMF or DMSO. ${ }^{1} \mathrm{H}-\mathrm{NMR}$ data showed that the polymer was fully deprotected, which was indicated by the lack of peaks in the region of $\delta=1.0-1.7 \mathrm{ppm}$. The hydrolytic stability of this carbohydrate analogue polymer towards acidic media (see above) is much better with respect to that of natural carbohydrates containing acetal linkages in the backbone. The solubility behaviour of these new pseudofuranose derivatives is very similar to that of e.g. cellulose (cellulose is water insoluble, methyl cellulose with up to $45 \%$ ether bonds is water soluble), thus indicating that the pseudopolyribofuranoses are likely to exhibit superstructures via intermolecular hydrogen bonding. The structure-property relationships of these new polyribofuranose analogue compounds will be investigated in more detail.

The authors gratefully acknowledge financial support by the European Union (TMR-Project GLASSCYCLICS Contract No. FMRX-CT97-0116). We thank Sven Kasper and Christina Schmutz for technical assistance and Professor Walter Burchard for many helpful discussions relating to the characterization of polyhydroxy compounds.

\section{Notes and references}

1 Y. C. Lee and R. T. Lee, Acc. Chem. Res., 1995, 28, 321.

2 M. Witvrouw, J. Desmyter and E. DeClercq, Antiviral Chem. Chemother., 1994, 5, 345.

3 K. H. Mortell, M. Gingras and L. L. Kiessling, J. Am. Chem. Soc., 1994, 116, 12053

4 M. C. Schuster, K. H. Mortell, A. D. Hegeman and L. L. Kiessling, J. Mol. Catal. A, 1997, 116, 209.

5 D. D. Manning, X. Hu, P. Beck and L. L. Kiessling, J. Am. Chem. Soc., 1997, 119, 3162

6 K. Nomura and R. R. Schrock, Macromolecules, 1996, 29, 540.

7 C. Fraser and R. H. Grubbs, Macromolecules, 1995, 28, 7248.

8 M. B. Clark and T. R. Lee, Polym. Prepr., 1998, 39(1), 416.

9 H. Prinzbach, H. Bringmann, J. Markert, G. Fischer and L. Knothe, Chem. Ber., 1986, 119, 589.

10 G. C. Bazan, J. H. Oskam, H.-N. Cho, L. Y. Park and R. R. Schrock, J. Am. Chem. Soc., 1991, 113, 6899.

11 B. M. Novak and R. H. Grubbs, J. Am. Chem. Soc., 1988, 110, 960.

12 T. J. Boyd and R. R. Schrock, Macromolecules, 1999, 32, 6608.

13 M. Lautens, A. S. Abd-El-Azis and G. Schmidt, Macromolecules, 1990, 23, 2819.

14 (a) R. Haag, R. Zuber, S. Donon, C.-H. Lee, M. Noltemeyer, K. Johnson and A. de Meijere, J. Org. Chem., 1998, 63, 2544; (b) R. Haag, A. Sunder and J. F. Stumbé, J. Am. Chem. Soc., 2000, 122, 2954.

15 P. Hadwiger and A. E. Stütz, Synlett, 1999, 11, 1787. 